\title{
FoodSMART: A mobile phone application to provide personalised information on the foods available in an eating out situation
}

\author{
K.M. Appleton ${ }^{1}$, J. Bray ${ }^{1}$, I. Mavridis ${ }^{2}$, A. Giboreau ${ }^{3}$, F.J.A. Perez-Cueto ${ }^{4}$, M. Ronge ${ }^{5}$ and \\ H. Hartwell ${ }^{1}$ \\ ${ }^{1}$ Bournemouth University, Poole, UK, ${ }^{2}$ University of Macedonia, Thessalonika, Greece, ${ }^{3}$ Institut Paul Bocuse, Ecully, \\ France, ${ }^{4}$ University of Copenhagen, Copenhagen, Denmark and ${ }^{5}$ Ronge \& Partners, Baden, Austria.
}

Eating out has become an integral part of modern living, but meals consumed out of the home are often high in calories and fat ${ }^{(1)}$. Providing information on foods and dishes (e.g. on nutritional content, allergens, and food provenance) has been associated with improved dietary intakes, but concerns have also been expressed ${ }^{(2,3)}$. Consumers welcome increased information, but only if the information is easily accessible and relevant to them ${ }^{(2,3)}$. This work aimed to develop a mobile phone application (app) to allow consumers easily accessible personalised information on the foods and dishes provided in an eating out situation.

The app is intended for use in workplace canteens, where a predetermined food menu offers a number of dishes and side-dishes per day. Initial stages of app development gained the information that consumers would like to receive about the foods provided, the information they would like to be able to personalise, and how this information should best be presented ${ }^{(3)}$. An app was then developed consisting of a user interface attached to a secure database. The database stores information per dish, as supplied by food manufacturers and caterers. The user interface allows consumers to input preferences about the information per dish that they receive. The app is activated by scanning a QR code on a menu, to provide information easily, and the consumer then receives the information they desire.

Following initial development, the app was demonstrated to consumers at eight public engagement events (four in the UK (79 respondents), one in France (54 respondents), one in China (48 respondents), one in Malaysia (34 respondents) and one in Denmark (18 respondents); and assessed using the 10-item System Usability Scale (SUS) questionnaire ${ }^{(4)}$, plus an additional question 'I believe the FoodSmart App will be useful to customers in a canteen setting to help them to get informed about dishes offered'.

A total of 233 respondents provided usable data: 81 (35\%) males, $143(61 \%)$ females $(9(4 \%)$ preferred not to provide gender); 115 $(49 \%)$ aged 20-29 years, $39(17 \%)$ aged $30-39$ years, $35(15 \%)$ aged $40-49$ years and $32(14 \%)$ aged 50 years and over (12 (5\%) preferred not to provide age). The mean overall SUS score was 68.3 of a possible 100 (sd.: 15.4, range: 27.50-100). All 10 questions, plus the additional question were responded to positively ( mallest $\mathrm{t}(229)=26.40, \mathrm{p}<0.05$ ), suggesting the app was positively received. The SUS scores gained are typical of those for other similar IT equipment, such as mobile phones and modems ${ }^{(5)}$. SUS scores were also comparable for males and females and no linear trend with age was found (largest $\mathrm{t}(196)=0.81, \mathrm{p}=0.42$ ).

These findings demonstrate positive consumer perceptions of the app, from a wide range of consumers, and suggest promise in terms of engagement and use. Impacts of the app on dietary choices will be ascertained in future work.

This work was funded by grant EU-H2020-RISE-634999: FoodSMART.

1. Lachat C, Nago E, Verstraeten R et al. (2012) Eating out of home and its association with dietary intake: a systematic review of the evidence. Obes Rev 13, 329-46.

2. Brinberg D, Axelson ML, Price S (2000) Changing food knowledge, food choice, and dietary fiber consumption by using tailored messages. Appetite 35, 35-43.

3. Price S, Viglia G, Hartwell H et al. (2016) What are we eating? Consumer information requirement within a workplace canteen. Food Qual Pref 53, $39-46$.

4. Brooke J (2013) SUS: A Retrospective. Journal of Usability Studies 8, 29-40.

5. Bangor A, Kortum PT, Miller JT (2008) An Empirical Evaluation of the System Usability Scale. Int J Human-Computer Interaction 24, 574-594. 